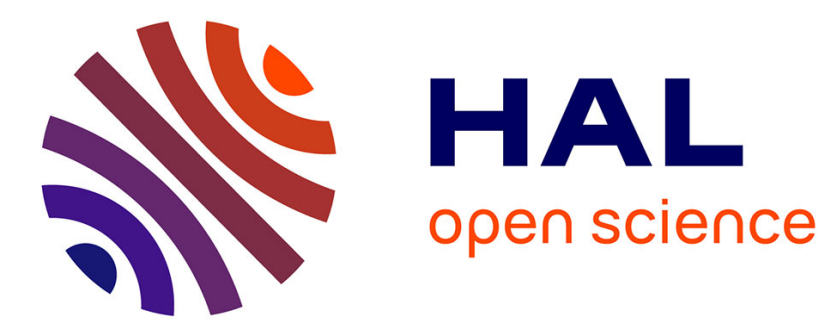

\title{
LASER INDUCED DIRECT WRITING OF ALUMINIUM
}

\author{
V. Shanov, B. Ivanov, C. Popov
}

\section{To cite this version:}

V. Shanov, B. Ivanov, C. Popov. LASER INDUCED DIRECT WRITING OF ALUMINIUM. Journal de Physique IV Proceedings, 1991, 02 (C2), pp.C2-373-C2-380. 10.1051/jp4:1991245 . jpa-00249835

\section{HAL Id: jpa-00249835 https://hal.science/jpa-00249835}

Submitted on 1 Jan 1991

HAL is a multi-disciplinary open access archive for the deposit and dissemination of scientific research documents, whether they are published or not. The documents may come from teaching and research institutions in France or abroad, or from public or private research centers.
L'archive ouverte pluridisciplinaire HAL, est destinée au dépôt et à la diffusion de documents scientifiques de niveau recherche, publiés ou non, émanant des établissements d'enseignement et de recherche français ou étrangers, des laboratoires publics ou privés. 
Colloque C2, suppl. au Journal de Physique II, Vol. 1, septembre 1991

\title{
LASER INDUCED DIRECT WRITING OF ALUMINIUM
}

\author{
V. SHANOV, B. IVANOV and C. POPOV \\ Technological University of Sofia, Department of \\ Semiconductors, 1756 Sofia, Kliment ohridski st. 8, Bulgaria
}

\begin{abstract}
Maskless configuration of aluminium has been grown by using visible light of a copper laser for pyrolytic decomposition of trimethylaluminium (TMA). The process was carried out in vacuum or argon and hydrogen atmosphere at partial pressure of TMA 0,5 and 5 mbar. The crystalline structure of the coating shows well defined grains. This morphology was observed for the first time by using pulsed visible laser. The Auger electron spectra indicate the presence of bonded oxygen and carbon incorporated into the aluminium. These elements cannot be totally avoided but their concentration can be reduced at the established optimum conditions to obtain low resistivity of the layer.
\end{abstract}

\section{Introduction}

Recently the classical method for aluminium deposition by sputtering has been successfully competed by metal organic chemical vapor deposition (MOCVD)/1/. The progressive development in this technology holds out the use of an appropriate laser beam, which is able to draw the configuration of interconnections directly on the wafer by scanning its surface. In this way, by stimulating selectively the reaction of chemical vapor deposition (CVD), it is possible to avoid the stage of photolithography.

In literature predominates the information about the photolytic decomposition of aluminium alkyls with eximer lasers emitting in an UV range of wavelengths $/ 2-4 /$, while experiments on the basis of pyrolysis of these compounds by laser emission are treated in a few articles $15,6 /$. In the publications, we know, there is a lack of information about the use of a visible pulsed laser and especially a copper laser with wavelengths of 510 and $578 \mathrm{~nm}$ for laser-induced chemical vapor deposition (LCVD) of aluminium that has directed our research to activation of chemical processes by such a laser. The pulsed time structure of the light source influences to a great extent the chemistry of the pyrolytic process, as well as the qualities of the deposit. Similar effects were observed by Comita 
et al using modulated $\mathrm{Ar}^{+}$laser beam /7/. They reported that the shape and the morphology of gold obtained by thermal LCVD were markedly different from depositis grown with an unmodulated beam. In case of pulsed laser, whose energy of a single pulse is extremely higher compared with modulated laser at the same wavelengths, these effects could appear in a larger degree. That was verified by our previous investigations of pyrolytic LCVD of aluminium /8,9/. A number of details in these processes concerning the conditions of deposition are still obscured which is a challenge for intensive scientific research.

\section{Experimental}

The deposition of aluminium layers was carried out by pyrolytic LCVD process using a focused up to 150 um beam of a copper laser on the surface of silicon monocrystalline wafer (111). The analysis included electrical resistance measurement by a two-point positioner connected with a digital ohmmeter and geometrical evaluation of the stripes by a light microscope and Talystep. The morphology was studied by scanning electron microscopy (SEM). Auger electron spectroscopy (AFS) was used to provide element analysis of the deposit. A scheme of experimental arrangement is given on Fig.l.

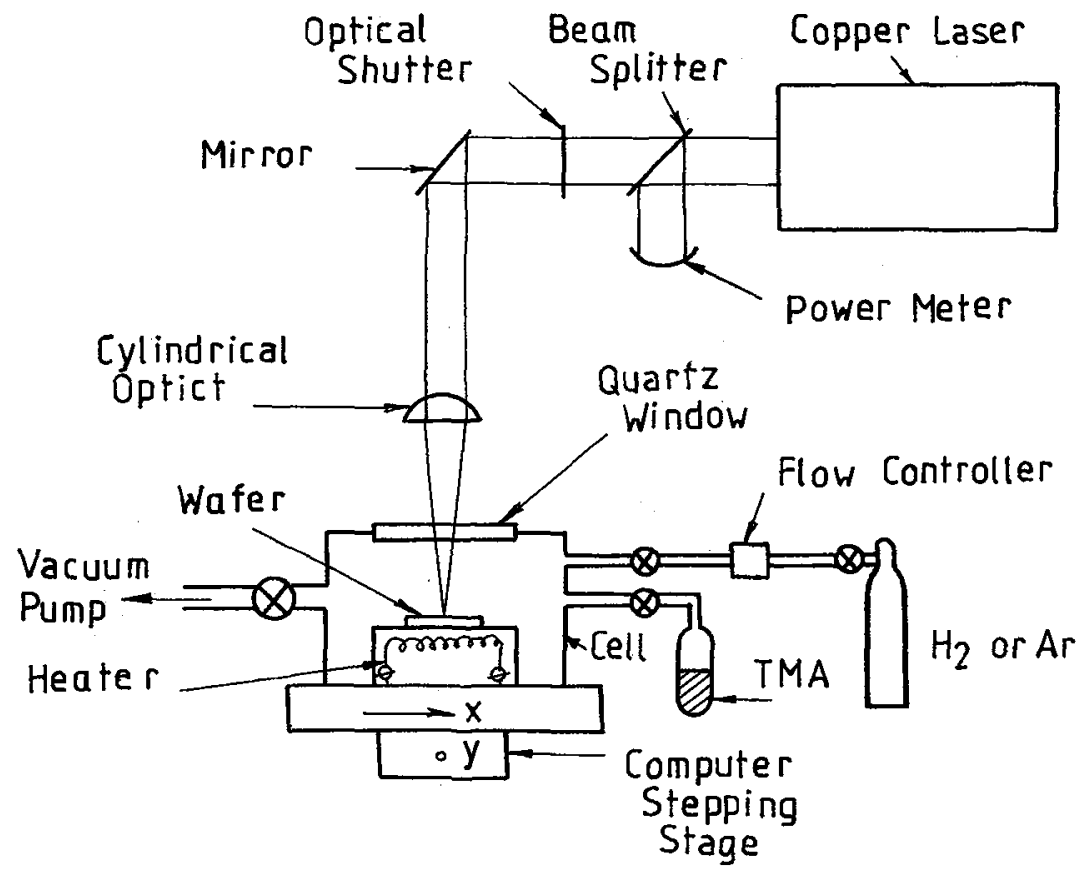

Fig.l. Fxperimental set-up for LCVD. 
The quality of aluminium layers with desired geometry during LCVD depends on a number of process parameters. The most important of them, we think, are the partial pressure of TMA; the presence of "buffer" gas, the laser beam power, the background temperature of the substrate and the writing speed.

In order to write the aluminium stripes with low resistivity, we varied the basic parameters in reasonable limits determined by the technical possibilities of the equipment and by the knowledge from our previous works $/ 8,9 /$. The writing speed was varied from 20 to $1000 \mu \mathrm{m} / \mathrm{s}$ and the pressure of TMA - from 0,5 to $10 \mathrm{mbar}$. Argon or hydrogen were used as "buffer" gases and the total pressure in the chamber was chosen from the range of 0,5 to 1020 mbar. The power of the laser was varied between 0,8 and $1,6 \mathrm{~W}$, and the background temperature of the substrate - from $300 \mathrm{~K}$ to $573 \mathrm{~K}$.

\section{Results and Discussion}

The laser beam power distribution determines the profile of the deposited material. As shown on Fig.2, Fig. 3 and Fig.4 the height of the stripes decreases with the increase of the writing speed. This is an expected effect due to the decrease of laser exposure time and surface temperature /10/. It should be noticed that the thickness of Al stripes obtained in hydrogen atmosphere is smaller compared with those in argon atmosphere at the same process parameters - Fig.2. Probably the hydrogen is not an inert component during the pyrolytic LCVD on the substrate surface. Suzuki et al suppose the formation of

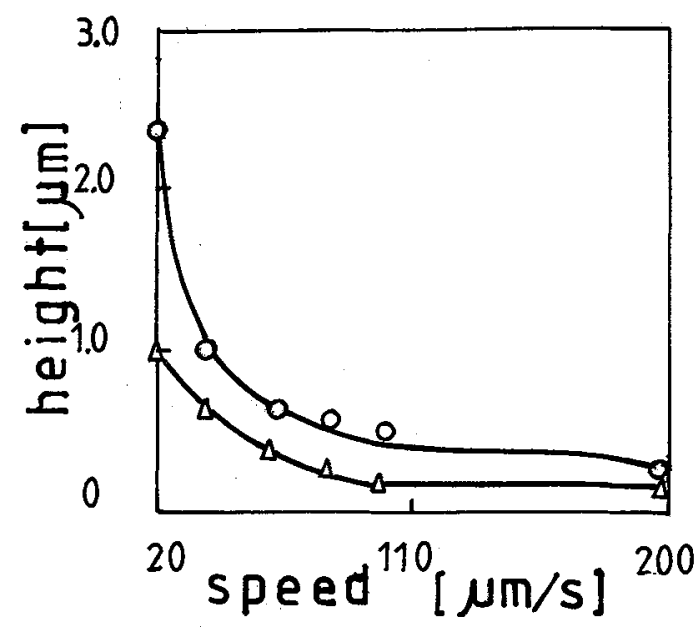

Fig.2. The average height of the deposit as a function

of writing speed at $1,6 \mathrm{~W}$ laser power

$\Delta-1$ mbar TMA + l atm $\mathrm{H}_{2} ; \mathrm{O}-1$ mbar TMA + 1 atm $\mathrm{Ar}$ 

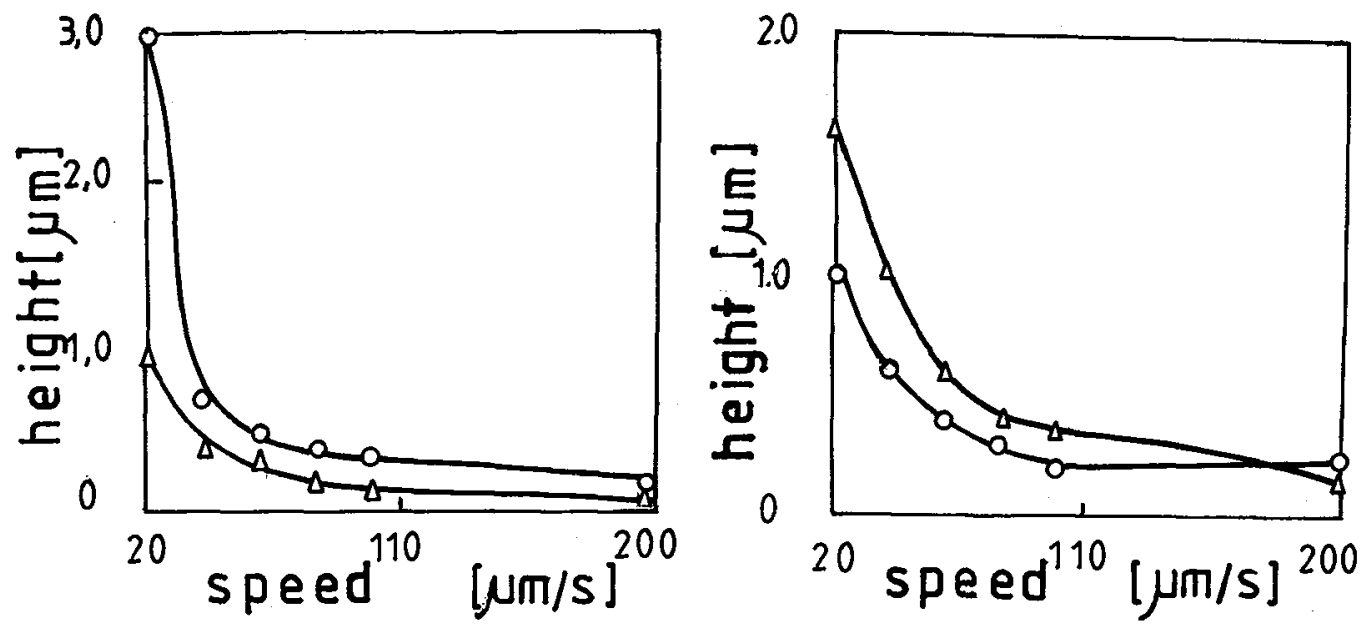

Fig.3. The average height of the deposit Fig.4. The average height of the deposit as a as a function of writing speed at $1,6 \mathrm{~W}$ function of writing speed at $1,6 \mathrm{~W}$ laser power laser power 1 mbar TMA + 1 atm $\mathrm{H}_{2}$

$\Delta-10$ mbar TMA + $90 \mathrm{mbar}^{\mathrm{H}}$

$\Delta-373 K$

0 - 10 mbar TMA + 1 atm $\mathrm{H}_{2}$

$0-473 K$

active intermediates containing $\mathrm{Al}$ as a result of the decomposition of TMA. Their concentration has a decisive significance for the deposition rate at higher temperatures /11/. We assume that these radicals can interact with hydrogen and the final result could be their deactivation so they do not have a contribution to the layer growth. The argon as an inert gas does not affect decomposition chemistry and in this case the thickness of the deposit is higher.

As shown on Fig. 3 the height of the stripes increases with the increase of the total pressure in the reaction cell. Following the hypothesis for intermediates, we suppose a decrease of their molecular diffusivity at higher pressure. This effect suppresses the diffusion of the intermediates away from the substrate and increases their dwell time on the surface reaction area. In this way the probability for their further decomposition to Al increases in the microreaction zone.

The influence of the nature of the "buffer" gas and the total pressure in the reaction cell on the thickness of the layer is more strognly expressed at $20 \mu \mathrm{m} / \mathrm{s}$ writing speed in comparison with the higher scanning velocities. We assume that it is due to the prolonged time of laser exposure at $20 \mu \mathrm{m} / \mathrm{s}$.

The thickness of the stripes depends on the background temperature created by a resistance heater - Fig.4. The height of the layer is smaller at higher temperatures at the same process parameters. This is probably a result of the exothermic character of the 
deposition. The negative value obtained for the enthalpy change $\Delta H_{\text {dep }}$ for the deposition reaction of Al from TMA including the enthalpy of methyl radicals desorption is $-16,8 \mathrm{kcal} / \mathrm{mol}$ at $298 \mathrm{~K} / 12 /$, which could explain the background temperature influence.

The morphology of the deposited aluminium shows well defined grains which are more typical for photolytic deposition of metals - Fig.5a. The grains' size depends strongly on the process parameters. The obtained layer's structures, we believe, was observed for the first time using pyrolysis of metal alkyls with a visible laser light. This type of morphology originates probably from the pulsed time structure of the light source, in which the power flux to the substrate for the time of a single pulse is about $274 \mathrm{GW} / \mathrm{m}^{2}$. This may cause an increase in supersaturation and high nucleation rate, which favour the granular structure. The size of the grains decreases with the increase of the writing speed as a result of surface temperature decrease. The size of the grains also increases with the increase of laser power and at 1,6 W secondary melting and crystallization of aluminium are possible - Fig.5b. Similar phenomenon is observed by Comita et al who suggest that the surface melting of the deposited gold is due to the heat released by the exothermic decomposition of reactant adsorbed during the time when the intensity of the modulated $\mathrm{Ar}^{+}$laser beam is off /7/. The increase of partial pressure of TMA from $1 \mathrm{mbar}$ to 10 mbar results in almost double decrease of grains' size which could be caused by the increase of supersaturation.

The depth profile of the basic elements ( $\mathrm{Al}, \mathrm{C}, \mathrm{O}, \mathrm{Si}$ ) is shown on Fig.6. Oxygen in the layer is due to the residual molecules in a gaseous phase and the native $\mathrm{SiO}_{2}$ on the surface of the substrate. There are two possible reasons for the considerable content of
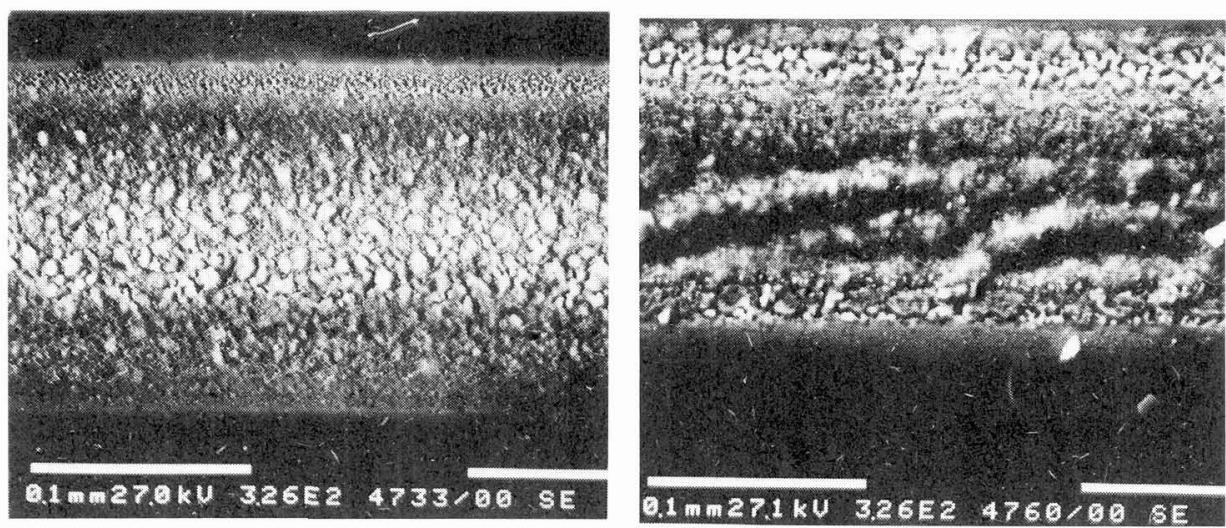

Fig.5 - Scanning electron micrographs of aluminium stripes obtained at $20 \mu \mathrm{m} / \mathrm{s}$ writing speed, Imbar TMA
a) 1,0 W laser power
b) 1,6 W laser power 


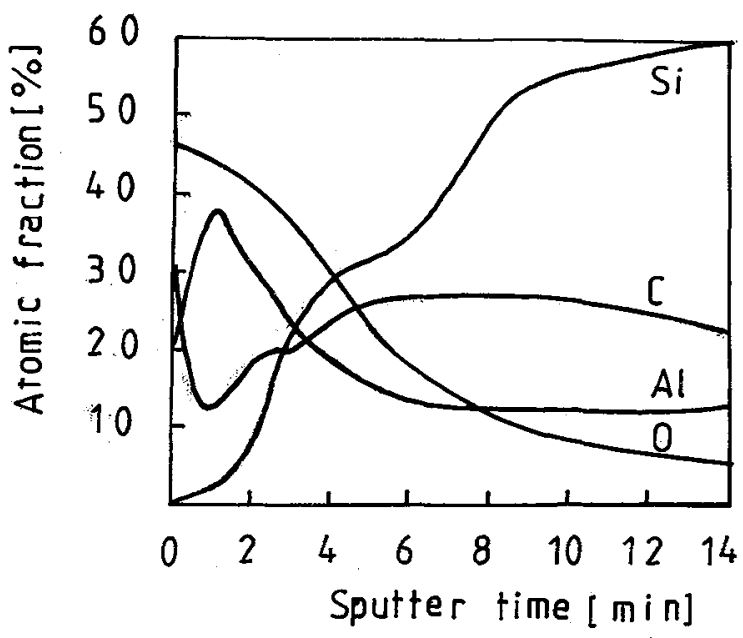

Fig.6. Depth profile of the stripe obtained at $100 \mu \mathrm{m} / \mathrm{s}$ writing speed;

$1,0 \mathrm{~W}$ laser power; 1 mbar TMA; 300K

silicon: background signal from the wafer or obtained solid solutions of Si and Al. The presence of aluminium as an unbound element is proved by the Auger spectra. The content of carbon is due to TMA whose mechanism of pyrolysis determines its incorporation in the deposit. It is almost impossible to avoid the carbon contemination in aluminium layer when using TMA as an $\mathrm{Al}$ source. The established elements in the layer could form metaloxycarbide which has conductivity near to that of the pure metal matrix /15/.

The resistivity of each stripe was calculated after the evaluation of the geometric parameters and the resistance. The lowest value obtained was $90 \mu \Omega . c m$. This resistivity occupies an intermediate place regarding the classical materials used for interconnections in IC technology: doped polysilicon $(2000 \mu n . \mathrm{cm})$ and silicides of Ti, Co, Mo, W $(13-35 \mu n \mathrm{~cm}) / 16,17 /$. In general, the resistivity decreases with the increase of the writing

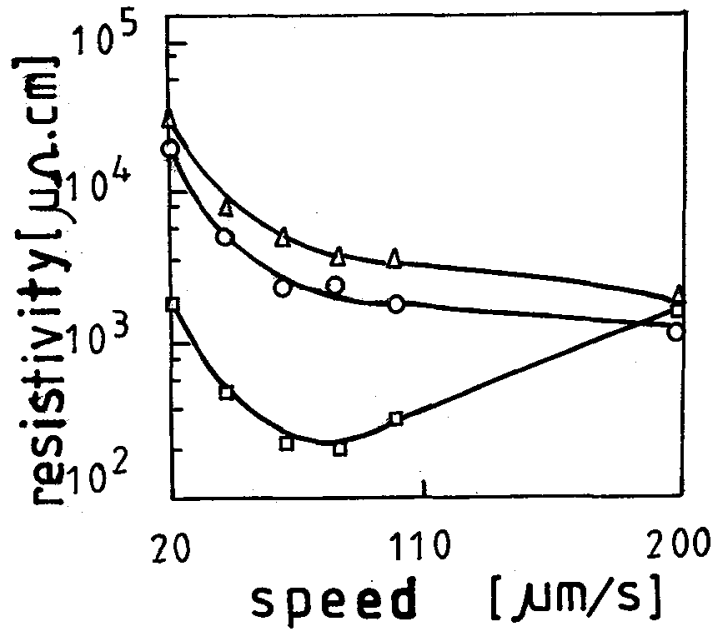

Fig.7. The resistivity as a function of writing speed at $373 \mathrm{~K} ; 1,6 \mathrm{~W}$ laser power 口- 1 mbar TMA; $\triangle$ - 1 mbar TMA + 1 atm $H_{2} ; 0$ - 1 mbar TMA + 1 atm Ar 
speed in the range of $20-80 \mu \mathrm{m} / \mathrm{s}-\mathrm{Fig.7}$. This behaviour is probably due to the decrease of the grains' size and the aluminium layer compaction. The presence of hydrogen or argon in the reaction cell increases the resistivity of the stripes. "Buffer" gas rises the total pressure causing decrease of the molecular diffusivity of the residues like $\mathrm{CH}_{X}$ and $\mathrm{Al}\left(\mathrm{CH}_{3}\right)_{x}$ created at the thermal decomposition of TMA /18,19/.

In this way, the probability for their incorporation in the layer is higher which influences the resistivity. From the other hand, it is known that the deposition rate of pyrolytic LCVD process is much more higher than that of conventional CVD and capture of "buffer" gas molecules is probable. That could additionally decrease the layer conductivity. The detection of $\mathrm{H}_{2}$ and $A r$ in the deposit by AF.S was not possible. Other methods for elemental surface analysis is necessary in this case.

\section{Conclusions}

In summary, we have reported laser-induced pyrolytic deposition of aluminium with a new light source - pulsed visible copper laser. The pulsed time structure of the laser beam causes granular surface morphology of the deposit which is not typical for thermal L.CVD of aluminium. The quality of the stripes can be set to obtain geometrical parameters suitable for repairing transparent defects on photomasks and resistivity values reasonable for interconnections in IC technology.

A challenge still remains concerning the study of decomposition mechanism of aluminium alkyls on a wafer caused by laser pyrolysis. New knowledges in this field achieved by in situ gaseous phase diagnostics with a quadrupole mass spectrometer combined with surface analysis of the layers could improve the coating qualities. Such experiments are currently underway.

\section{Acknowledgement}

The generous financial support by the Ministry of Science and Higher Education is gratefully acknowledged. 


\section{References}

1. R.A.Levy, M.L.Green, P.K.Gellagher, J.Flectrochem.Soc., 131 (1984) 2175

2. Y.Zhang and M.Stuke, J.Crystal Growth, 93 (1988) 143

3. J.Y.Tsao and D.J.Fhrlich, Appl.Phys.Lett., 45 (1984) 617

4. T.Mottoka, S.Gorbatkin, D.Lubben, Djula Fres, J.F.Greene,

J.Vac.Sci.Technol.A, 4 (1986) 3146

5. Y.Rytz - Froidevaux, R.Salathe, H.Gilgen, Phys.Lett. 84A (1981) 216

6. M.Oprysko, M.Beranek, P.Young, IFEE EDL, 6 (1985) 344

7. P.B.Comita,P.E.Price, T.T.Kodas, Mat.Res.Soc.Symp.Proc., 158 (1990) 7

8. V.Shanov, M.Iankova, B.Ivanov, Pat.Reg.No.76035 (1986)

9. V.Shanov, M.Iankova, B.Ivanov, Annual Reports of Higher Institute of Chemical Technology, Vol. 30, No.2 (1990) 156

10. Y.I.Nissim, A.Licotoila, R.B.Gold, Y.F.Gibbons, J.Appl.Phys., 51 (1980) 274

11. N.Suzuki, Ch.Analayama, K.Masu, K.Tsubouchi, N.Mikoshiba, Jap.J. of Appl.Phys., 25 (1986) 1236

12. R.L.Jackson. T.H.Baum, T.T.Kodas, D.J.Ehrlich, G.W.Tyndall, P.B.Comita, Laser Microfabrication Thin Film Processes and Lythography/ edt. by D.J.Ehrlich and J.Y.Tsao, Academic Press Inc., Lonidon, (1989) 428

13. Y.Rytz-Froidevaux, R.P.Salathe, Proc. of SPIE, 469 (1984) 55

14. C.Garrido-Suarez, D.Broichotte, H. van den Bergh, Appl.Phys.A, 46 (1988) 285

15. A.F.Wells, Structural Inorganic Chemistry, Vol.3, Mir, Moscow, Russian end., (1988), p.53

16. Y.Paulean, Solid State Technol. 4 (1987) 155

17. Y.Paulean, Solid State Technol. 2 (1987)61

18. F.Lee, T.R.Gow, R.Lin, A.L.Backman, D.Lubben, R.I.Masel, Mat.Res.Soc.Symp.Proc., 131 (1989) 339.

19. D.W.Squire, C.S.Dulcey, M.C.Lin, J.Vac.Sci.Technol.B, 3 (1985) 1513. 